\title{
LA ÉTICA INDOLORA. LAS ALTERNATIVAS ECOPACIFISTAS
}

\author{
Juan Sisinio Pérez Garzón \\ Universidad de Castilla-La Mancha
}

\begin{abstract}
Resumen: Se plantea la tesis de que el desarrollo de una ética ecopacifista puede considerarse una revolución histórica. La idea de revolución no tiene por qué ceñirse a la violencia y destrucción. En este artículo se rescatan las propuestas y formas de cambio social basadas en principios noviolentos y de armonía con la naturaleza. Se aporta una reflexión básica sobre el despliegue de una ética noviolenta y de una ética ecologista. Ambas, con la figura de Thoreau como punto de partida, y con el denominador común de haber subvertido los valores colectivos y los comportamientos individuales. Junto con el feminismo, han ampliado rotundamente el campo de los derechos y las metas de la justicia social.
\end{abstract}

Palabras clave: Cambio social, Revolución noviolenta, Ecologismo, Ecofeminismo.

The painless ethics. Ecopacifist alternatives

Abstract: The thesis is that the development of an ecopacifist ethics can be considered a historical revolution. The idea of revolution need not be traced to violence and destruction. This article rescues proposals and forms of social change based on nonviolent principles and harmony with nature. It provides a basic reflection on the deployment of a nonviolent ethic and an ecological ethic. Both, with the figure of Thoreau as a starting point, and with the common denominator of having subverted collective values and individual behaviors. Along with feminism, they have broadly expanded the field of rights and social justice goals.

Keywords: Social change, Nonviolent revolution, Ecologism, Ecofeminism.

El concepto de revolución alberga habitualmente la idea de ruptura violenta de una realidad establecida, sea política, social, económica o cultural. Quizá se deba a los propios fundamentos de una civilización que desde sus orígenes ha sacralizado la violencia con mitos, ritos y héroes, tal y como ha desentrañado en una obra ya clásica René Girard. Persisten hasta el presente en prácticamente todas las ideologías. Bastaría recordar a este respecto el ritual trágico y espectacular del actual terrorismo que hace del sacrificio y de unos cuerpos inmolados, tanto de víctimas como de victimarios, el soporte del mensaje social (Girard, 1995 [1972]).

Data de recepció: 22 d'octubre de 2017 / Data d'acceptació: 16 de gener de 2018. 
Es lógico, por tanto, que las ciencias sociales hayan colocado la violencia en un lugar preeminente en la teoría social y en los análisis de los cambios en la historia. La bibliografía al respecto es inmensa, y cuenta con aportaciones realizadas desde todas las especialidades. Aunque minoritarias, a lo largo del siglo XX se han desplegado, en contrapartida, nuevas perspectivas tanto científicas como éticas que tratan de revertir la hipnosis cultural que existe en torno a la célebre metáfora de la violencia como "partera de la historia", metáfora que Karl Marx formuló no porque la violencia produjera por sí misma los cambios sino porque ayudaba a dar a luz a nuevas formas sociales.

En efecto, desde la modernidad ilustrada se ha impuesto la idea de que el progreso implica necesariamente una alta dosis de violencia. En su práctica totalidad, las ideologías políticas han asumido que la violencia es inherente a la sociedad y comparten la definición de Max Weber sobre el Estado como el monopolizador de la violencia física, esto es, como la única fuente de derecho legitimada para ejercer tal coerción. Convivimos, por tanto, con la idea de que existe una violencia legítima y otra ilegítima, y debatimos sobre sus lindes, solapamientos y potenciales vuelcos de legitimidad, según quién la ejerza. De ahí que se considere lógico que una revolución incluya siempre el acto de violencia necesario para desplazar a los anteriores detentadores de la "otra" violencia legal.

No se pretende abordar en estas páginas ni siquiera un somero balance del complejo e inacabado debate sobre las opciones básicas de relación entre grupos humanos, si la guerra o la cooperación, ni sobre los progresos culturales en la moral, sus causas y sus momentos de avance o retroceso. Existen numerosas aportaciones y argumentos, tanto de las ciencias biológicas como de los saberes humanísticos (Waal, 2007 y 2011; Nowak y Highfield, 2012; Wilson, 2012; Castro, López-Fanjul y Toro 2003 y 2008). Se plantea un objetivo más simple: exponer que es posible desunir la acostumbrada fusión existente entre revolución y violencia, porque se puede cumplir con su significado etimológico de ruptura o transformación radical respecto al pasado inmediato sin necesidad de que la muerte se erija en protagonista de los cambios sociales.

Existen suficientes estudios científicos que han rescatado los datos que permiten calibrar la reducción de los niveles de violencia en la organización y cambios producidos en las sociedades. Han subrayado, por un lado, el papel de la cooperación y del altruismo en la evolución humana y, por otro, la creciente eficacia de las ideas e instituciones pacificadoras para asentar el progreso moral en los distintos ámbitos de la convivencia humana. Quizás sean suficientes las referencias a algunos de los autores de mayor influencia y de distintas ramas científicas, como Edward O. Wilson, Steven Pinker, Frans de Waal, Martin Nowak o Yuval Noah Harari (Pinker, 2012; y Harari, 2015 y 2016). De igual forma, la 
expansión de los valores ecológicos, sobre todo desde las últimas décadas del siglo XX, permite afirmar que éstos han convulsionado los planteamientos tradicionales de dominio del hombres sobre los demás seres vivos y han creado una nueva conciencia de maridaje con la naturaleza.

Si en la práctica totalidad de los libros de historia se explica el pasado con hitos casi siempre violentos, sean guerras o revoluciones, y normaliza que el hombre es el rey del universo, vale la pena, en contrapartida, sacar del olvido los idearios que sustentan una ética indolora. No se puede negar que los momentos de máxima violencia social y los modos abrumadores de explotación de la naturaleza han supuesto también notables cambios en la historia. Sin embargo, en este dossier dedicado a la revolución "de nuestro tiempo", parece adecuado centrar estas páginas en reflexionar sobre las propuestas y formas de cambio social basadas en principios noviolentos y de armonía con la naturaleza. Sin duda, son ideas y razones que, por otra parte, hay que ligar con las nuevas revoluciones científicas en marcha (genética, neurociencia, nanotecnología...) porque todo ello constituye el vislumbre de un futuro que algunos intelectuales ya catalogan como "transhumanista" (Hughes, 2004).

\section{ESLABONES ORIGINARIOS Y CONVERGENCIA DE IDEAS}

Lo que hoy, en las primeras décadas del siglo XXI, podríamos definir como ética ecopacifista ha sido resultado de la confluencia de distintos movimientos sociales, en concreto del pacifismo, el ecologismo y el feminismo, formulados originariamente en el siglo XIX y desarrollados a lo largo del siglo XX. En su evolución y práctica se han caracterizado por carecer de esas estructuras de organización jerarquizadas y, por tanto, disciplinadas, propias de los movimientos políticos, pues no han aspirado a la conquista del Estado sino sobre todo al cambio de valores y comportamientos tanto de las personas como de la sociedad en su conjunto. En este sentido, el feminismo, el pacifismo y el ecologismo han compartido principios y han expandido derechos necesarios y válidos para toda sociedad. En consecuencia, en las actuales democracias occidentales la mayoría de los partidos políticos ha integrado en sus programas el derecho a la igualdad de las mujeres junto a dosis más o menos relevantes de valores ecológicos y una persistente aspiración a la paz, incluso para, llegado el caso, justificar la guerra.

Puesto que el feminismo tiene su correspondiente capítulo en este dossier y es, por sí solo, un movimiento con rango de auténtica revolución, siempre pacífica, procede destinar estas páginas al proceso de configuración de una ética basada en valores de noviolencia y de ecologismo. En la búsqueda de sus 
orígenes, aparece una vez más la fecha mítica de 1848. Si en este año se puede datar la partida de nacimiento tanto del movimiento feminista como del socialista, también lo fue para el ideario ecopacifista.

Así, en 1848 el Manifiesto comunista redactado en Londres por dos jóvenes revolucionarios, Marx y Engels, explicó y afirmó el movimiento de emancipación de los trabajadores, mientras que en Nueva York, Elisabeth Cady Stanton y Lucrecia Mott, en la Declaración de sentimientos de Seneca Falls, enunciaron con rotundidad los derechos de igualdad de las mujeres. Justo en esos mismos años también se gestaron las experiencias y las obras de Henry David Thoreau, guías incuestionables de las prácticas de ecologismo, noviolencia y desobediencia civil. Tanto el escrito comunista y la proclamación feminista como las obras de Thoreau tuvieron impactos muy limitados en su momento. Han sido los posteriores desarrollos históricos de los diferentes movimientos sociales los que, reconstruyendo sus orígenes, han destacado el valor de tales propuestas. Significativamente en los manuales de historia universal al uso, en cualquier nivel educativo, figura el Manifiesto comunista como fuente del ulterior despliegue de fuerzas socialistas. Sin embargo, ni se menciona la Declaración de sentimientos de Seneca Falls ni se hace alguna referencia al alcance de la personalidad de Thoreau. Ni el feminismo ni el ecologismo y la noviolencia parece que hayan logrado superar esa criba pedagógica que estipula lo que debe aprenderse de la historia universal.

Es justo, por tanto, subrayar las aportaciones básicas de Thoreau, autor rescatado y vigente hoy en el mundo editorial. En sus obras Walden y Desobediencia Civil se encuentran formulaciones de nuevos procedimientos de acción social, derivadas de dos principios: primero, que un gobierno nunca puede actuar más que con los poderes que le otorguen los propios ciudadanos; y segundo, que debemos pensar el progreso sin explotación de personas y sin destrucción de la naturaleza. Concibe el progreso, por tanto, solo si se logra una vida de armonía con los recursos y bellezas que ofrece la naturaleza. Tal sería el medio para alcanzar una sociedad justa y equitativa. Por eso, mientras Marx pensaba que la emancipación de los obreros implicaría la liberación de todas las demás clases sociales, Thoreau exigía ante todo que cada persona comenzara dicha emancipación por sí mismo, liberándose de las ataduras impuestas por los distintos poderes (Thoreau, 2015 [1849]; y 2005 [1854]). De igual modo, las feministas, en esos años luchaban por abolir tanto la subordinación de las mujeres como la esclavitud de la población negra estadounidense. Eran tres movimientos con una misma ética de rebelión contra la injusticia y la dominación. Tuvieron un eco muy escaso en su día, pero lanzaron a la palestra de la historia diagnósticos y soluciones para superar las injusticias generadas por 
los nuevos modos de poder y explotación que el capitalismo desplegaba sobre las personas y sobre los recursos naturales.

No corresponde desentrañar las distintas facetas del pensamiento de Thoreau en estas breves páginas. De sus obras cabría extraer incluso tesis contrapuestas. Basta con enfatizar que Thoreau sentó el germen de la noviolencia en su meta de abolir el Estado, sin exigir un Estado alternativo, ni siquiera el proletario. En este sentido es importante subrayar que, frente al liberalismo y el marxismo, despojó de legitimidad al empleo de la violencia. No justificó ni la violencia coercitiva del Estado en la vida cotidiana, ni tampoco la revolucionaria de los oprimidos para subvertir el orden existente (Casado da Rocha, 2005).

En el camino abierto por Thoreau el pensamiento y las actividades de William Morris fueron otro eslabón importante. Sus reclamos de vida armónica con lo natural y de un consumo responsable, en oposición a los hábitos generados por la nueva sociedad industrial, han ejercido una influencia significativa, aunque en su pensamiento coexistan propuestas contradictorias (Morris, 2004 [1887]; y Thompson, 1988). Tuvo mayor eco social en su día, en las décadas del cambio del siglo XIX al XX, el pensamiento de insumisión y paz de Tolstoi. Su radio de influencia fue muy considerable y alcanzó a distintas ideologías políticas con propuestas que han sido catalogadas como anarcopacifismo y cristianismo anarquista (Rolland, 2010 [1911]; y Blanch, 2013). Es destacable a este respecto la correspondencia que mantuvo al final de sus días con Gandhi, cuando éste se encontraba todavía en Sudáfrica luchando por los derechos de los indios en aquella colonia británica (Barlett, 2012).

Estos precedentes intelectuales ejercieron una influencia muy dispar. Probablemente fueron más decisivas ciertas experiencias históricas cuyo valor hay que rescatar para conocer el despliegue de una trayectoria específica, con ejemplos relevantes de posibles caminos hacia una revolución sin armas ni violencia. Hay que subrayar como ejemplo precursor los movimientos de no-resistencia que se desarrollaron en los Estados Unidos contra el esclavismo y a favor de la igualdad de las mujeres en las décadas centrales del siglo XIX. Estas acciones colectivas crearon tradición tanto en el feminismo como en posteriores luchas por los derechos civiles en los Estados Unidos (Anderson y Zinsser, 2009).

Por otro lado, en Irlanda, junto a formas de lucha violenta, la resistencia de los agricultores arrendatarios a pagar rentas abusivas a los terratenientes se ejemplarizó en el enfrentamiento con Charles C. Boycott, administrador de un aristócrata terrateniente, cuyo empeño en obligar a los campesinos a pagar las rentas impuestas terminó con el triunfo de los arrendatarios. Éstos encontraron amplios apoyos sociales y todos "boicotearon" aceptar contratos o trasladar el ganado y los productos de las tierras administradas por el citado Boycott. Desde 1880 la prensa definió esta forma de resistencia social con el término de "boi- 
cotear". También en Irlanda se dieron otros modos de resistencia como las huelgas de hambre, con el notorio caso del político del Sinn Féin Terence MacSwiney, que murió en 1920 tras 74 días en huelga de hambre para protestar por su encarcelamiento, tras ser juzgado por un tribunal militar, lo que contribuyó enormemente a la derrota del gobierno británico ante la opinión pública internacional (Ranelagh, 1999).

Por lo demás, justo en estas primeras décadas del siglo XX alcanzaron un despegue formidable los movimientos sociales que reivindicaban nuevas metas políticas sin practicar la violencia. Fueron años de auge del pacifismo, precisamente mientras las potencias se lanzaban a la carrera armamentística que desembocó en la tragedia de 1914. Justo fue el momento en que se consolidaron las ideas y estrategias catalogables como noviolentas. Por un lado, el sufragismo feminista subvirtió las formas de lucha contra la desigualdad jurídica y contra el monopolio de poderes ejercido por los varones; por otro, el pacifismo irrumpió en la política con voz propia y se plasmó sobre todo en los movimientos de objeción de conciencia al servicio militar durante la Primera Guerra Mundial. A todo esto se sumó el enorme impacto que tuvo la praxis de Gandhi, enfrentado al imperio más poderoso del momento. Conviene, por tanto, exponer las claves básicas de las contribuciones de aquellas primeras décadas del siglo XX y el posterior desarrollo de la teoría política de la noviolencia.

\section{EL IMPACTO DE GANDHI Y LAS APORTACIONES A LA NOVIOLENCIA}

En las décadas previas a la Primera Guerra Mundial se desarrolló un movimiento pacifista que sumó energías sociales desde distintos frentes. Cabe destacar cuatro frentes. Quizás en primer lugar el pacifismo feminista que ligó el sometimiento de las mujeres a la prepotencia del varón, cuyo ejemplo más obvio era el militar, por lo que lucharon contra el gasto militar y contra la guerra, aunque desde 1914 surgió una fuerte escisión por este motivo en el seno del feminismo. En segundo lugar, el pacifismo científico representado por Alfred Fried, para quien la paz era requisito para organizar el progreso de la ciencia y de un mundo justo. En tercer y cuarto lugar hay que considerar, por un lado, las voces que dentro del socialismo y del anarquismo enarbolaron ideas pacifistas y, por otro, los cristianos que realizaron una interpretación pacifista de los textos evangélicos, como los cuáqueros, los menonitas y también los antes citados seguidores de Tolstoi (López, 2004).

Sin duda, feminismo y pacifismo se han desarrollado como mecanismos de vasos comunicantes, aunque no haya una relación unívoca en todos los mo- 
mentos. Cabe señalar dos factores al respecto: por un lado, el feminismo desde sus primeros momentos ha rechazado la violencia como solución tanto para los conflictos sociales y políticos como para los personales; por otro, las prácticas de las movilizaciones feministas han optado por crear redes de solidaridad cotidiana entre mujeres, anónimas y colectivas, sin las jerarquías organizativas habituales en la política. En definitiva, la conjunción de pacifismo con feminismo implica la construcción de una ciudadanía organizada en democracia paritaria, lo que subvierte las jerarquías y los espacios de exclusión y obliga a la equidad económica y cultural en el disfrute de los derechos y deberes ciudadanos, algo que, en principio, menguaría drásticamente las posibilidades para ejercer la violencia y, por tanto, la guerra. Es revelador a este respecto recordar los nombres de las mujeres que han obtenido el premio Nobel de la paz, desde Bertha von Suttner en 1905 y Jane Addams en 1931, hasta Alva Myrdal (1982), Rigoberta Menchú (1992) y Malala Yousafzai (2014), entre otras.

Por eso, aunque el pacifismo no sea un movimiento privativo de las mujeres, lo cierto es que fueron decisivas las sufragistas de las primeras décadas del siglo XX y, en concreto, las que se opusieron a la Primera Guerra Mundial. Mientras importantes sufragistas apoyaron la guerra por nacionalismo, pensando defender mejor así a sus hijos, otras disintieron y crearon la Liga Internacional de Mujeres por la Paz y la Libertad (WILPF), tras el congreso de La Haya de abril de 1915, donde más de mil mujeres procedentes de doce países, con sus Estados en guerra entre sí, no sólo denunciaron los horrores de la contienda sino que diseñaron estrategias de paz y buscaron formas de mediación para detener la tragedia. Aquella Liga, la WILPF, con sus siglas en inglés, sigue hoy en activo y es la organización pacifista feminista más antigua del mundo, con importantes programas a favor del desarme y del respeto a los derechos humanos y a la protección del medio ambiente (Anderson y Zinsser, 2009).

En las décadas bisagras entre el siglo XIX y XX también se produjo una vigorosa corriente pacifista en los ambientes intelectuales. Cabría remontarse al antecedente de la fundación de la Cruz Roja en 1859 por Henry Dunant, y sobre todo al impacto de la obra de Jean de Bloch, La guerre de l'avenir, donde diagnosticó en 1895 las potencialidades destructivas de las nuevas armas bélicas, e influyó en importantes diplomáticos de las potencias del momento para organizar las Conferencias de paz de la Haya de 1899 y 1907. Estas conferencias plantearon por primera vez, al menos en el nivel teórico y con buenas intenciones, establecer un freno al desarrollo de nuevas armas y congelar los gastos militares. No se cumplieron tales deseos, pero no hay que infravalorar el precedente que aportaban para colocar la paz como el valor supremo en las relaciones internacionales. Justo en esos años Alfred Nobel determinó que uno 
de los premios que se concedieran con el fondo que instituyó fuera el premio Nobel de la Paz.

En todo caso, el momento crucial se produjo al desencadenarse las enormes e inéditas formas de violencia que marcaron la Primera Guerra Mundial. Hubo respuestas antagónicas. Por un lado, la exaltación del furor bélico por autores como Ernst Jünger, por citar solo un ejemplo célebre, pero sobre todo la inclusión de la violencia como estrategia política desde la década de 1920, especialmente en las filas comunistas y fascistas. En el lado contrario, el pacifismo se manifestó de forma rotunda en los inéditos movimientos de objeción a las armas que realizaron miles de jóvenes británicos reclutados para la guerra, con un importante protagonismo de los cuáqueros. La campaña de objeción fue intensa y eficaz, organizada por políticos como Arnold Rowntree y Edmund Harvey, miembros de la "Sociedad Religiosa de los Amigos", nombre oficial de los conocidos como cuáqueros, también por el socialista pacifista Keir Hardie, y apoyada por prestigiosos intelectuales como Bertrand Russell y John Maynard Keynes, entre otros, de modo que en 1916 el Parlamento británico incluyó dicha objeción como causa para no ser alistado en el ejército. Simultáneamente, en Francia e Italia, miles de soldados se negaban a volver al infierno de las trincheras; y también en Rusia la deserción en las tropas se convirtió en acicate decisivo para el desplome del poder zarista.

Cabe destacar, por otra parte, el enorme peso intelectual de Bertrand Russell, que perdió su cátedra en Cambridge y sufrió prisión por defender a los objetores de conciencia. Tanto Russell como el científico Albert Einstein y el escritor Romain Rolland contribuyeron a prestigiar las posiciones noviolentas, aunque ante todo eran opuestos a las guerras injustas y no tanto unos pacifistas en sentido filosófico o teórico. En concreto, Rolland no solo biografió a Tolstoi como adalid de la paz, sino que su temprana biografía de Gandhi, publicada en 1924, se convirtió en referencia para expandir por Europa las ideas del líder indio e inspirar un activismo basado en la teoría de la noviolencia (Rolland, 2010 [1911]). Por lo demás, no hay que olvidar el peso de las ideas de paz propagadas por otros afamados intelectuales como Anatole France o Herbert G. Wells. Destacó por su activismo y por tratar de darle bases científicas al pensamiento pacifista el vienés Alfred Hermann Fried, cuya trayectoria comenzó en la década de 1890, al alimón con la baronesa Von Stunner, la primera mujer con Premio Nobel de la Paz (1905), y luego él mismo también galardonado con idéntico premio en 1911.

En todo caso, junto a los intelectuales occidentales y los movimientos de oposición a la guerra antes citados, más los promovidos en la década de 1920, como la International Fellowship for Recontiliation (IFOR, fundada en 1919), 
o la War Resisters International (WRI), no cabe duda de que la principal aportación a la construcción de una ética noviolenta se produjo en la India. El pensamiento y la actividad de Gandhi deben ser valorados legítimamente como el anclaje decisivo de las posteriores teorías de la noviolencia.

En efecto, Gandhi, aunque no fue el único inventor de tácticas noviolentas, sistematizó el concepto de noviolencia. Reconoció como precedentes el impago de impuestos que desencadenó la revolución independentista de los Estados Unidos, las movilizaciones sufragistas de las feministas, las ideas de Tolstoi, el ejemplo de la huelga general de 1905 en Rusia o el boicot de los chinos a los productos norteamericanos en 1906. Eran ejemplos que Gandhi no los pensó como simples tácticas para alcanzar el poder u organizar otras estrategias políticas, sino como argumentos para fundamentar una teoría sociopolítica que hacía de la noviolencia tanto un medio como un fin. Pensaba sobre todo en la liberación física y espiritual de cada persona, sin ningún tipo de constricción opresiva, y, como consecuencia, se lograría idéntica liberación para la sociedad, en este caso la de una India sometida a un poder colonial. Por eso planteó su lucha por la independencia desde una ética que causara el menor sufrimiento posible en uno y otro bando. No se trataba de una simple resistencia pasiva, como hasta entonces habían practicado movimientos precedentes, o de una objeción de conciencia, como los antimilitaristas durante la primera Guerra Mundial, sino de una activa coerción no-violenta, como se tradujo en el libro de Clarence Marsh Case en 1923, y que ya usaba Gandhi con la palabra "ahimsa", compuesta de la partícula privativa "a" precediendo al sustantivo "himsa", que significaba violencia (Case, 1923).

Por supuesto, el pensamiento de Gandhi era más complejo, pues la noviolencia partía de la idea de que nunca podemos estar seguros de tener toda la verdad cuando defendemos una posición política. Por eso no solo debemos respetar a quienes tienen posturas distintas, por muy opuestas que sean, sino incluso actuar con generosidad de modo que el adversario llegue a cambiar de ideas o actitudes. Con tal premisa, al no existir la verdad absoluta en unos determinados fines, no se deben emplear nunca medios que produzcan dolor en los oponentes y, en consecuencia, hay que situar en la táctica política la persuasión moral por encima de la coerción. Diseñó así tres fases de acción política, la persuasión en primer lugar, para convencer racionalmente; luego, el sacrificio con acciones noviolentas para ganar adeptos, y, por último, la nocooperación que ya es la coacción directa y masiva para disuadir al adversario de que no trate de imponer sus criterios u órdenes (Gandhi, 2008 y 2014).

Por otra parte, es importante subrayar que en Gandhi también hubo una filosofía social que propugnaba comunidades con autosuficiencia económica, basada en una moral opuesta a los valores de especulación y explotación capitalista 
y, en contrapartida, con fórmulas catalogables de equilibro ecológico entre recursos naturales y capacidades del trabajo manual. Esta última faceta no tuvo el mismo éxito que la idea de la noviolencia, pero no se puede obviar por lo que aportó a una nueva ética ecológica. En concreto, fue vegetariano no por gastronomía sino por ética, porque se oponía al sacrificio de animales, y defendió la reforestación y la salubridad ambiental.

En definitiva, en estas páginas no se pretende explicar la obra y actividad de Gandhi, porque hay libros que las explican con precisión y sólido discernimiento (López, 2017), sino destacar que desde entonces su ejemplo y sus ideas constituyeron hitos decisivos en la construcción de una ética alternativa a la dominante. Tuvo seguidores directos, como Vinoba Bhave con el movimiento Sarvodaya en la misma India, los pacifistas norteamericanos que desde la década de 1930 fundaron ashrams, lugares de convivencia similares a los monasterios, o el italiano Lanza del Vasto que también fundó una comunidad de militancia noviolenta y ecológica, en una de cuyas sedes, la existente cerca de Elche de la Sierra (Albacete) murió en 1981. Cierto que la figura de Gandhi cambió de signo la valoración de la estrategia de noviolencia, pero no fue un caso aislado. Muy próxima geográfica y culturalmente fue la figura, también memorable, de Abdul Gaffar Khan, conocido como el Badshah Khan, quien desde 1920, entre el pueblo pastún de Pakistán, elaboró un pensamiento noviolento que ha influido en movimientos musulmanes cuyas estrategias noviolentas han sido relevantes, como, por ejemplo, la primera Intifada de los palestinos en 1987-1993.

De nuevo, la enorme tragedia que supuso la Segunda Guerra Mundial produjo respuestas aparentemente dispares, pero todas unidas en al afán de no repetir semejante cataclismo humano. Por un lado, en las décadas de posguerra se intensificó el estudio de las guerras y genocidios, un modo de vacunar a las sociedades futuras contra las ideas que llevaron a tal conflagración, y, por otro, se fortalecieron los movimientos e instituciones con fines de erradicar la violencia de la vida política, desde las ONGs de solidaridad humanitaria hasta la ONU, sin olvidar la creación de la Comunidad Europea y, por supuesto, los movimientos de objeción militar y de conquistas de paz.

Sin embargo, paradójicamente en la segunda mitad del siglo XX fueron elevados a la categoría de mitos ciertos líderes que, como Mao Zedong, Che Guevara, Ho Chi Ming, e incluso Meinhoff, en un país tan desarrollado como Alemania, preconizaron una violencia revolucionaria con la que enfervorizaron a multitud de seguidores. Es cierto que, en contrapartida, desde el decenio de 1960, se anudaron movimientos sociales con estrategias pacíficas tan potentes como el de la lucha por los derechos civiles de los afros en Estados Unidos, con Martin Luther King al frente. También hubo decisivas aportaciones desde las filas del feminismo, ecologismo e indigenismo, que integraron en sus idea- 
rios las estrategias noviolentas fraguadas en la primera mitad del siglo, y las aplicaron en sus luchas sociales y políticas a favor de los excluidos.

No por casualidad, fue en 1968 cuando una joven politóloga, Judith Stiehm, diagnosticó y diferenció las dos concepciones de la práctica de la noviolencia: una, basada en principios éticos, como la de Gandhi y Martin Luther King, y otra asumida solo de forma pragmática. Para ésta el pacifismo no es tanto una teoría válida para toda la sociedad sino un método más efectivo para alcanzar determinados fines políticos (Stiehm, 1968). Semejante pragmatismo estratégico fue sistematizado por Gene Sharp en 1973. Ha sido el estratega de los métodos noviolentos pragmáticos, con una enorme estela de seguidores y con un indudable ascendiente en medios políticos y académicos. Ha demostrado que los métodos de acción noviolenta (desde la persuasión y protesta, los boicots y huelgas, la provocación de encarcelamientos masivos hasta la toma de instituciones alternativas) producen mejores beneficios que la violencia. Permiten una participación más amplia, con niños y ancianos incluidos; se puede organizar abiertamente; logra que sea mal vista una respuesta violenta por parte del poder; y también recurre al voto, todo ello con el fin de desafiar la legitimidad del poder existente e implantar una legitimidad alternativa. Por eso se considera una noviolencia pragmática, pues no se apoya en una ética de paz ni predica una sociedad sin violencia, sino que utiliza métodos noviolentos como simple instrumento para imponer otra forma de poder o de organización social, cuyos fines incluso a veces se silencian. Parte de la tesis de que no existe un poder monolítico y, por tanto, se le puede derrocar mediante una desobediencia capaz de crear otra legitimidad y otro poder en paralelo (Sharp, 1968 y 2014).

Es importante apuntar las contradicciones de esta versión pragmática de la noviolencia, sistematizada por el citado Gene Sharp. Este estudioso de Thoreau y Gandhi fundó en 1983 la Institución Albert Einstein y se encumbró desde 1990 como teorizador de los "golpes blandos" para derrocar sistemas de gobierno, una estrategia que a posteriori se ha interpretado como la utilizada por los movimientos anticomunistas de los países bajo la órbita soviética en la década de 1980. Es cierto que Sharp no ha pensado que los métodos noviolentos sean la estrategia para construir una sociedad alternativa al capitalismo; simplemente los ha considerado los más aptos y seguros para deslegitimar dictaduras y derribar sistemas totalitarios, y para construir, en contrapartida, unas democracias representativas.

Por eso, por tener una ideología liberal democrática, se ha propagado la idea de que los generales norteamericanos y la CIA se han adueñado de su estrategia, que, al ser noviolenta, pueden vender como buena en sí misma, como parte de la democracia, aunque sea solo un envoltorio de legitimidad democrática para alcanzar fines antidemocráticos. Se han propagado, en consecuen- 
cia, versiones fraudulentas sobre movimientos sociales de extrema complejidad social, como, por ejemplo, la "revolución naranja" de Ucrania en 2004-2005. Es más cómodo dejarse llevar por la paranoia conspirativa, reduciendo a oscuras maniobras de los agentes de la CIA los abundantes factores que concurren en dicho movimiento social. En cualquier caso, es cierto que las jerarquías militares estadounidenses han incluido en sus estudios de defensa nacional el concepto de "disuasión civil", en cuya estrategia son formados los agregados militares de las embajadas, porque se ha expandido la conciencia de que los métodos noviolentos han logrado un predicamento social insoslayable.

Por otra parte, los estudiosos de la noviolencia han desarrollado estrategias de defensa y resistencia con base fundamentalmente civil, frente a la tradicional idea de defensa militar de unos derechos o de un país. En esta nueva faceta no solo hay que considerar al citado Gene Sharp, destacan también las aportaciones de Johan Galtung, Theodor Ebert y Robert J. Burrowes, todos con la idea de construir una sociedad donde se destierre la posibilidad de que el poder militar sea el baluarte ineludible para una democracia. Coinciden en apreciar la democracia como organización política que impide una guerra interna en la correspondiente sociedad, porque existen instituciones y procedimientos para encauzar los conflictos de modo noviolento. Sin embargo, piensan que esa democracia alberga la contradicción de dejar en manos de los militares la defensa y seguridad del sistema político, de modo que, en caso de violencia, el gobierno del pueblo se tiene que apoyar en el poder militar, con todos los riesgos ya consabidos que las estructuras militares implican.

En contrapartida, defienden el método de la defensa civil para el triunfo de la paz como principio y práctica en todos los niveles sociales. Por eso estos autores buscan fórmulas para aminorar el peso de la defensa militar y desplegar, en contrapartida, modos de defensa civil y social (López, 2017). Si Gene Sharp piensa la defensa civil como una ampliación de la protección civil ya existente, Burrowes y Galtung, sin embargo, en la estela de Gandhi, la dotan de un fuerte carácter social, al convertir a todas las personas en protagonistas de una defensa popular basada en la ética de la noviolencia. Así, no se trataría de métodos de noviolencia puramente pragmática sino que implicarían la transformación alternativa de toda la sociedad, al proponerse la erradicación de la violencia estructural y de otras formas de alienación, y la creación desde abajo de una comunidad con formas de poder autogestionario (Galtung, 1985 y 2003; y Castañar, 2013).

En definitiva, las nuevas propuestas enfatizan sobre todo la necesidad de establecer la ética radical de la noviolencia abriendo debates concretos sobre el gasto militar en el mundo, la contención del mismo y, como alternativa, las urgentes respuestas que reclaman la pobreza o la educación en amplias regiones 
del planeta. Por un lado, existe una creciente producción intelectual sobre los factores estructurales y estratégicos que convergen en los procesos de resistencia civil; por otro, las nuevas tecnologías de la información y la comunicación ofrecen nuevas oportunidades de eficacia a la resistencia civil para estar vigilantes contra cualquier violación de derechos humanos, y para compartir métodos y experiencias de diferentes contextos histórico-internacionales. A eso se suma la necesidad de cambiar en las ciencias sociales la idea dominante que identifica poder popular con lucha armada, como si ésta siempre fuera más exitosa.

En todo caso, desde el último tercio del siglo XX es muy destacable el crecimiento de ONGs y de movimientos sociales que impulsan una ética noviolenta. A sabiendas de las limitaciones políticas existentes en unos Estados que cada año gastan miles de millones de dólares en presupuestos de defensa armada, sin embargo luchan por construir cotas crecientes de paz en todos los ámbitos sociales. No sólo protestan contra las violencias existentes, sino que despliegan ese modo de actuar ejemplificado en el coraje cívico de Mandela, quien fue capaz de controlar el odio a sus carceleros transformando la venganza en cooperación con sus adversarios y en base para una nueva sociedad.

\section{NATURALEZA Y ECOLOGÍA: CAUSAS Y FINES DE REVOLUCIÓN}

La ética medioambiental se ha desarrollado en la práctica a la par que la de la noviolencia, pues ésta, en definitiva, no sólo atañe a las relaciones con las personas, también obliga a ser practicada en todos los entornos de lo humano. En cualquier caso, la conciencia de una relación específica con la naturaleza como madre de toda la vida se ha planteado con formulaciones claramente diferenciadas. Existen significativos precedentes en la construcción de una moralidad ambiental, desde Francisco de Asís hasta Rousseau y los románticos alemanes, para llegar otra vez a Henry David Thoreau como pionero fundador del pensamiento ecológico.

El hecho es que, desde finales del siglo XIX, en las sociedades más industrializadas se ha desarrollado una ética ecológica, con aportaciones desde diferentes perspectivas que, con cierta frecuencia, se han solapado (Parra, 1984; y Dobson, 1997). Se puede esquematizar en tres modelos prescriptivos o actitudes e ideas: los conservacionistas, los ecologistas y los ambientales. Comparten tal amplitud de posibilidades que, en la práctica, a lo largo del siglo XX y hasta la actualidad, permiten cobijar planteamientos que tanto pueden ser asumidos o rechazados por la izquierda política como por la derecha, por reducir la clasificación política a este par ideológico. 
Así, por ejemplo, el conservacionismo, concepto que se aplica al pensamiento y actividad que se limita a defender la protección de los hábitats de flora y fauna frente a los cambios producidos por los avances tecnológicos, puede ser integrado fácilmente por el capitalismo que genera tales avances tecnológicos. A la vez, puede chocar frontalmente con la idea de comunismo definido por Lenin como "el poder de los soviets más la electrificación", una fórmula que, además de los destrozos producido en la antigua URSS, ha llevado a China a ser quizás el país más contaminado y contaminante del planeta.

Los conservacionistas se apoyan en estudios científicos y presionan para que se respeten los hábitats existentes. Fueron pioneros en los Estados Unidos, país donde nació durante el último tercio del siglo XIX la fórmula de parques nacionales protegidos por el gobierno y se fundaron las primeras organizaciones conservacionistas, en 1886 la Audubon Society, que tomó el nombre del ornitólogo John James Audubon, y en 1892 el Sierra Club, precedente de las posteriores ONG ecologistas, fundado por el botánico John Muir. En Gran Bretaña fueron las mujeres las que en 1889 crearon la Real Sociedad para la Preservación de las Aves, en un principio para frenar la matanza de aves con cuyas plumas se adornaban los sombreros. Las tres asociaciones mantienen su actividad hoy en día, y cuentan con socios de distintas y opuestas ideologías políticas. Hubo movimientos similares en otros países hasta llegar a la creación en 1948, con apoyo de la UNESCO, de la Unión Internacional para la Conservación de la Naturaleza (UICN), actual Unión Mundial para la Naturaleza, que en 1961 constituyó el Fondo Mundial para la Vida Salvaje (WWF), hoy Fondo Mundial para la Naturaleza.

Por su parte, el ecologismo significa no sólo protección de la naturaleza, sino también una activa movilización para lograr que los gobiernos y los empresarios asuman sus propuestas de defensa del medio ambiente. Es un movimiento social propio de países desarrollados, con partida de nacimiento en la Universidad de Berkeley donde se creó el primer grupo de activismo ecologista, Ecology Action. Su novedad política consistió en objetar el modelo de desarrollo capitalista, no desde principios políticos y sociales como el socialismo y comunismo, los modelos alternativos hasta entonces, sino que la meta de abolir la explotación del hombre la integraron en otro objetivo más amplio, el de suprimir con urgencia la explotación de la naturaleza. Coincidían con las izquierdas clásicas en lograr la emancipación de las personas, pero dentro de la defensa del hombre como parte de la naturaleza y del consiguiente freno radical del desarrollo capitalista.

Por otra parte, el ecologismo como movimiento social se apoyó en la ciencia, pues la Ecología, que contaba con estudios previos en las distintas ramas 
de las ciencias naturales (botánica, zoología, etc.), adquirió el rango de disciplina independiente. Se definió como especialidad que integraba y sintetizaba las distintas ciencias de la vida para investigar y explicar los nexos existentes entre los organismos vivos y sus distintos entornos.

En definitiva, en el último tercio del siglo XX la defensa de la naturaleza tuvo su eclosión como nuevo frente de lucha social y política, siempre con la ciencia como argumento, originalidad que se debe enfatizar. La onda expansiva fue de enorme calado porque, al tradicional conservacionismo y al naciente ecologismo, se sumó una tercera opción catalogable como ambientalismo. Los ambientalistas se conducían con criterios derivados de estudios científicos, buscaban ante todo garantizar una vida humana de calidad material, sin destruir otras formas de vida ni expoliar los recursos naturales. En esta órbita se movió la Conferencia de la Biosfera convocada en 1968 por la UNESCO en París, donde se planteó por primera vez la necesidad de juntar el uso y la conservación de los recursos naturales, y se acordó la creación de la figura de "reserva de la biosfera", para proteger determinados hábitats de modo que se les aplicasen medidas sólo de un desarrollo sostenible.

En 1970 el llamado Club de Roma juntó a científicos del MIT, liderados por Dennis L. Meadows, con políticos y empresarios, para estudiar los "límites del crecimiento". Sus resultados se publicaron en 1972 con unas conclusiones pesimistas sobre el fin de los recursos para el año 2000, y la catástrofe casi absoluta para el año 2100, si se seguían los ritmos de crecimiento demográfico y de explotación de recursos naturales ejecutados a lo largo del siglo XX. Fue un libro, conocido como "Informe Meadows", que alcanzó un impacto extraordinario, con debates que expandieron entre amplias capas de las poblaciones occidentales una creciente conciencia de crisis en todo el planeta por el expolio de los recursos naturales, creando miedo también a la catástrofe (Ehrlich y Ehrlich, 1993).

Esas preocupaciones tuvieron una temprana expresión en el mismo año de 1972, en la conferencia internacional convocada por la ONU en Estocolmo para tratar en exclusiva la crisis detectada por los ecólogos, con el fin de pensar medidas de defensa del medio ambiente. Se lanzó el concepto "desarrollo sostenible", un nuevo paradigma de progreso social que situaba a las personas como parte de la naturaleza y, por tanto, defendía un progreso basado en la armonía de las necesidades de todos los seres vivos y de los propios recursos del planeta. Desde entonces, gracias a estos debates que expandieron la conciencia de la degradación ambiental, crecieron de forma exponencial los grupos y organizaciones ecologistas, nacionales o internacionales, en su mayoría con el propósito de influir en los gobiernos para implantar medidas que obligaran a empresas y ciudadanos a defender el equilibrio medioambiental. 
De este modo, desde finales del siglo XX, el movimiento ecologista se puede considerar ramificado en tres dimensiones: la conservacionista antes citada, la institucional, y la propiamente militante en la vida política, con exigencias más o menos radicales (Doherty, 1996; y Dobson, 1997). Los conservacionistas tratan de que no entren en conflicto las exigencias científicas de la Ecología con las demandas económicas de las actuales sociedades desarrolladas. Se les ha llamado "capitalistas verdes", porque no cuestionan el sistema económico sino que, por el contrario, ponen precio al uso de los recursos naturales, con multas y castigos a quienes no cumplan las normas de conservación del medio ambiente. De hecho ha surgido un amplio despliegue de nuevos negocios con todo lo que ahora se etiqueta como "verde", calificativo que vende la garantía de respeto a la naturaleza y a las leyes que la protegen. En los países desarrollados la economía verde representa un porcentaje creciente de un capitalismo que no ha mermado su capacidad de negocio y explotación, aunque a la vez permite catalogar importantes áreas del planeta como reservas naturales para la biodiversidad.

El ecologismo institucional se encuentra en gran medida relacionado con el conservacionista, pero también recoge las demandas de movimientos sociales como las plataformas, agrupaciones y ONGs ecologistas que, desde la década de 1970, han desplegado campañas de agitación política para lograr que sean los Estados los garantes del equilibrio ecológico. Específicamente institucionales son los partidos verdes, creados y organizados para defender un programa ecologista dentro de los cauces que conforman los Estados (Muller-Rommel y Poguntke, 2002). Aunque no procede enumerar el amplio listado de tales agrupaciones, hay que citar al menos la importancia mundial de Greenpeace, fundada en Canadá en 1971, autofinanciada, sin apoyos ni de gobiernos ni de partidos políticos, y protagonista de campañas de enorme impacto internacional.

En definitiva, desde fines del siglo XX se ha implantado la consideración de la ecología como una ciencia insoslayable para la organización de la sociedad, y este hecho puede catalogarse de revolucionario porque ha introducido valores inéditos y una jerarquía de prioridades en prácticamente todas las capas sociales. Cierto que, al convertirse lo ecológico en un criterio aceptado por ideologías y grupos sociales distintos e incluso contrapuestos, resulta paradójico aplicarle el carácter de factor revolucionario. Ahora bien, si por revolución se entiende un giro contundente en los valores e intereses humanos, se puede defender el rango de revolución histórica al hecho de que el medio ambiente, desde la década de 1980, se haya convertido en agente social y en materia de la agenda de las instituciones nacionales e internacionales (Latour, 2013).

Cierto es que lo ecológico puede albergar decisiones dispares pues siempre se encuentra en tensión con las nuevas necesidades que surgen de los avances tecnológicos y de las incesantes demandas de bienestar material. Por otra parte, 
no hay que olvidar que dentro de las propias investigaciones medioambientales se producen desacuerdos muy nítidos entre expertos porque ni todos los datos estadísticos son igualmente fiables, ni ofrecen una única interpretación. Hasta ahora se basan en muestras no siempre suficientes ni de larga duración; con frecuencia se identifica el valor estadístico con una explicación causal; y se ofrecen conclusiones que dan pie a la polémica, tal y como provocó la obra de Bjorn Lomborg, El ecologista escéptico (Lomborg, 2003 [1998]), al defender que la biosfera es un terreno tan escasamente investigado que requiere todavía enormes dosis de cooperación y humildad científica para no mezclar valores ideológicos y apriorismo con datos estadísticos en fase temprana de comprobación.

Por lo demás, el patrocinio de actividades con etiqueta de ecológicas se ha convertido en señal de distinción social y en actividad que compite con las viejas obras de caridad. Por ejemplo, el caso de la reina Noor de Jordania, nombrada presidenta de honor de BirdLife, la mayor agrupación mundial de asociaciones defensoras de las aves. Nada que ver con los partidos verdes que desde la década de 1980 replantearon los valores tradicionales de las izquierdas occidentales, en cuyo despegue fue decisivo el ejemplo y actividad del Partido de los Verdes fundado en Alemania en 1979, con una figura tan destacada como Petra Kelly.

Más extremo es el movimiento Animal Liberation Front-ALF, organizado desde 1976, activo en más de 40 países, funciona por células sin líderes, recurre a la acción directa de liberar animales, sean de granja para alimentación o de laboratorio para investigar, y ataca a quienes se benefician del sacrificio de cualquier animal. También se ha desarrollado una versión conocida como ecologismo profundo, basado en las teorías del pensador y político Arne Naess, donde los derechos de la naturaleza se transforman en pensamiento tan místico que deriva de hecho en una especie de religión panteísta, con dosis indudables de fundamentalismo, rotundamente coherente por el lado de la naturaleza, pero igualmente relativista por lo que se refiere a los valores culturales (Speranza, 2006). Así, en la práctica sus seguidores abandonan los entornos urbanos para organizarse en ecoaldeas, alternativa de raigambre socialista frente al consumismo capitalista que destruye la naturaleza. La primera experiencia se produjo en Dinamarca en 1991 y se han expandido a otros continentes, con el afán de hacer posible no solo el desarrollo sostenible sino también la diversidad cultural por las distintas formas de convivencia que se plantean en cada caso.

Por lo demás, junto a estas propuestas de mayor o menor esencialismo ecologista, raro es el gobierno que, sea del color político que sea, no cuente en la actualidad con un ministerio dedicado al medio ambiente. Hasta las antiguas concejalías municipales de basuras y limpieza han pasado a denominarse concejalías de medio ambiente. En gran medida lo verde se ha convertido también en parte del marketing para promocionar un producto como creación realizada 
dentro del canon de respeto a la naturaleza. De este modo, la enorme vastedad de contenidos políticos, económicos y emocionales que se albergan bajo la etiqueta de lo verde y de la defensa del medio ambiente, puede interpretarse como la banalización de la ciencia ecológica, sin duda, pero también como un estallido histórico que ha subvertido la idea de progreso predominante hasta el último tercio del siglo XX.

El ecologismo ha logrado, por tanto, que no se pueda plantear el progreso social sin una ética que abarque los derechos de los animales y de la biodiversidad del planeta. Además, ha generado medidas de políticas concretas, país por país, y también decisiones globales, enormemente zigzagueantes e incumplidas, como, por ejemplo, las adoptadas contra el cambio climático. En todo caso, es obvio que ya existe una nueva agenda que implica a todos los países en la defensa de lo ecológico, un hecho insólito, sin duda, en la historia de la humanidad. No sólo el comercio, el modo de producción capitalista, los medios audiovisuales o el turismo nos globalizan, también la ética medioambiental se ha convertido en un asunto planetario (Simonnet, 1980; Martínez Alier, 1992; y Russell, 2011).

\section{¿REVOLUCIONES SIN REVOLUCIONARIOS? REFLEXIONES A MODO DE EPÍLOGO}

En conclusión, el desarrollo de una ética ecopacifista puede ser valorado como una revolución. En general, en las ciencias sociales la idea de revolución se asocia con ciertos cambios históricos acompañados de violencia y destrucción. Además se le otorga a esos momentos el rango de salto cualitativo para marcar la ruta del proceso evolutivo que requiere el progreso humano. Semejante idea se ha cuestionado con frecuencia. Cabe pensar la revolución de forma más fértil y prolífica y comprender mejor la complejidad de los cambios sociales en la historia, porque la humanidad, en definitiva, no tiene predestinada una línea evolutiva con metas unívocas.

De este modo, tanto la ética de la noviolencia como la ecologista no solo cuestionan esa idea lineal y unidimensional de progreso, sino que también aspiran a revolucionar todos los niveles de la existencia, sea individual o social, pública o privada. Plantean, en consecuencia, una revolución global, un cambio de raíz en política, economía y, de modo muy especial, en cultura, pues no conciben separadas la acción colectiva de la coherencia individual. En efecto, esa ética ecopacifista no cabe ser externalizada, al modo clásico de las revoluciones políticas, ni se despliega gracias a organizaciones jerarquizadas con vistas a la conquista del poder estatal. Exige una práctica que afecta simultáneamente a 
todos los campos de la vida social y eso nos implica como individuos concretos. Por eso se podría hablar de que se trata de una propuesta revolucionaria sin esos agentes revolucionarios que tradicionalmente han configurado los movimientos sociales orientados al cambio en los poderes políticos y económicos.

Llegados a este punto, vale la pena recordar ciertas facetas del pensamiento de Vandana Shiva, pensadora que, aunque contenga tesis de un relativismo cognitivo extremo, aporta claves para desplegar una ética que entrelace el imperativo ecológico con el cambio social. Plantea la ecología como parte de los derechos humanos y también como soporte para desplegar una sociedad noviolenta, pues el principio de la no-violencia impide tanto dañar a los seres vivientes como a la propia naturaleza (Shiva, 1998 y 2006). En este camino conviene evocar igualmente las reflexiones del ecofeminismo sobre la creación de una sociedad socialista libertaria donde se implante una relación fehaciente de igualdad entre géneros y de armonía con la naturaleza (Riechmann, 2009). Cierto que tales propuestas encierran contradicciones importantes, con prácticas cercanas al "ludismo", o incluso directamente fantasiosas.

Por lo demás, estos movimientos, que convergen en una ética ecopacifista y feminista, implican la transformación de los saberes sociales. Los actuales compartimentos estancos por disciplinas no responden a los retos que surgen de las relaciones entre naturaleza, trabajo e invención de los humanos, y de cálculos sobre intereses, valores, justicia redistributiva y aspiraciones de igualdad y bienestar. Además, a tales aspiraciones hay que sumar las facetas inéditas que se derivan de la actual concatenación de revoluciones científicas en marcha en nuestros días. Se trata de novedades sin parangón en la historia. Ocurren en las ciencias de la vida, con la ingeniería genética al frente, las neurociencias y la biotecnología con una posible revolución agrícola ecológica; también en las ciencias físicas, con el nuevo material de grafeno y la nanotecnología, motor de otra revolución industrial con capacidades que nos resultan hoy ilimitadas.

Tal cúmulo de inventos nos obligan a reflexionar sobre la necesidad de armonizar las cosmovisiones existentes con las nuevas capacidades generadas por los conocimientos científicos. Las relaciones sociales y los entornos medioambientales se tienen que repensar sin esos esquemas deterministas predominantes hasta ahora. También se ven afectadas las ideas sobre nuestra capacidad de libertad, e incluso el misterio de lo consciente en el universo. En definitiva, tal y como ha sentenciado Ulrich Beck, estamos ante el fin de la antítesis entre naturaleza y sociedad. Esto modifica sustancialmente el paradigma humanista vigente, y exige explorar fórmulas éticas para vivir con las nuevas realidades de la computación cuántica, la vida sintética y la inteligencia artificial (Beck, 2006; Castro, 2008; Hughes, 2004; y Harari, 2016). 


\section{BIBLIOGRAFÍA}

ANDERSON, Bonnie S. y ZINSSER, Judith P. (2009): Historia de las mujeres: una historia propia, Barcelona, Crítica, 1272 p.

BARLETT, Rosamund (2012): Tolstoi. A Biografia, Rio de Janeiro, Biblioteca Azul, $640 \mathrm{P}$.

BECK, Ulrich (2006): La sociedad del riesgo: hacia una nueva modernidad, Barcelona, Paidós, 304 p.

BLANCH, Antoni (2013): Leon Tolstoi, un profeta político y evangélico, Barcelona, Cristianisme i Justícia, 31 p.

CASADO DA ROCHA (2005): Antonio, Thoreau. Biografía esencial, Madrid, Acuarela Editorial, $208 \mathrm{p}$.

CASAS SALINAS, Miquel (2017): El fin del Homo sapiens: la naturaleza y el transhumanismo, Madrid, Ápeiron, $132 \mathrm{p}$.

CASE, Clarence M. (1923): Non-violent Coercion. A Study on Methods of Social Pressure, New York-London, The Century Co., 375 p.

CASTAÑAR, Jesús (2013): Teoría e historia de la revolución noviolenta, Madrid, La Llevir-Virus, 327 p.

CASTRO, Laureano, LÓPEZ-FANJUL, C. y TORO, Miguel A. (2003): A la sombra de Darwin. Las aproximaciones evolucionistas al comportamiento humano, Madrid, Siglo XXI, 212 p .

CASTRO, Laureano, CASTRO, Luis y CASTRO, Miguel A. (2008): ¿Quién teme a la naturaleza humana?, Madrid, Tecnos, 557 p.

DOHERTY, Brian (1996): Democracy and Green Political Thought Sustainability, Rights and Citizenship, London, Routledge, $246 \mathrm{p}$.

DOBSON, Andrew (1997): Pensamiento político verde: una nueva ideología para el siglo $X X$, Barcelona, Paidós, $270 \mathrm{p}$.

DUBY, Georges y PERROT, Michelle (2000): Historia de las mujeres en Occidente, 5 vols., Madrid, Taurus Minor/Santillana.

EHRLICH, Paul y EHRLICH, Anne H. (1993): La explosión demográfica. El principal problema ecológico, Barcelona, Biblioteca Científica Salvat, 334 p.

GALTUNG, Johan (1984): Hay alternativas: 4 caminos hacia la paz y la seguridad, Madrid, Tecnos, $383 \mathrm{p}$.

GALTUNG, Johan (1985): Sobre la paz, Barcelona, Fontamara, 159 p.

GALTUNG, Johan (2003): Paz por medios pacíficos: paz y conflicto, desarrollo y civilización, Bilbao, Bakeaz, 354 p.

GANDHI, Mahatma (2008): Política de la Noviolencia. Antología, Edición de Rubén Campos, Madrid, La Catarata, 160 p.

GANDHI, Mahatma (2014): Autobiografía. Historia de mis experiencias con la verdad, Madrid, Gaia Ediciones, 400 p.

GIRARD, René (1995): La violencia y lo sagrado (ed. or., 1972), Barcelona, Anagrama, $338 \mathrm{p}$. 
HARARI, Yuval N. (2015): Sapiens. De animales a dioses: una breve historia de la humanidad, Barcelona, Debate, 492 p.

HARARI, Yuval N. (2016): Homo deus: breve historia del mañana, Barcelona, Debate, $489 \mathrm{p}$.

HUGHES, James (2004): Citizen Cyborg: Why Democratic Societies Must Respond to the Redesigned Human of the Future, Boulder, Westview Press, 294 p.

LATOUR, Bruno (2013): Políticas de la naturaleza. Por una democracia de las ciencias, Barcelona, RBA, 414 p.

LOMBORG, Bjorn (2003): El ecologista escéptico, Madrid, Espasa, 632 p.

LÓPEZ, Mario (2004): Enciclopedia de paz y conflictos, Granada, Universidad de Granada, 2 vols.

LÓPEZ, Mario (2017): ¿Noviolencia o barbarie? El arte de no dejarse deshumanizar, Madrid, Dykinson, 233 p.

MARTÍNEZ ALIER, Joan (1992): De la economía ecológica al ecologismo popular, Barcelona, Icaria, $219 \mathrm{p}$.

MORRIS, Williams (2004): Cómo vivimos y cómo podríamos vivir (ed. or. 1887), Logroño, Pepitas de Calabaza, 182 p.

MULLER-ROMMEL, Ferdinand y POGUNTKE, Th., eds. (2002), Green Parties in National Governments, London-Portland, OR: Frank Cass, 177 p.

NOWAK, Martin Nowak y HIGHFIELD, Roger (2012): Supercooperadores, trad. de Francesc Reyes Camps, Barcelona, Ediciones B, 400 p.

OFFEN, Karen (2015): Feminismos europeos, 1700-1950, Madrid, Akal, 555 p.

PARRA, Fernando (1984): Diccionario de ecología, ecologismo y medio ambiente, Madrid, Alianza Editorial, 288 p.

PINKER, Steven (2012): Los ángeles que llevamos dentro. El declive de la violencia y sus implicaciones, Barcelona, Paidós, 1103 p.

RANELAGH, J. O’B. (1999): Historia de Irlanda, Madrid, Cambridge University Press, $302 \mathrm{p}$.

RIECHMANN, Jorge y otros autores (2009): Claves del ecologismo social, Madrid, Editorial de Ecologistas en Acción, 224 p.

ROLLAND, Romain (2010): Vida de Tolstói (ed. or. 1911), Madrid, El Acantilado, $240 \mathrm{p}$.

RUSSELL, Edmund (2011): Evolutionary History: Uniting History and Biology to Understand Life on Earth, Cambridge, Cambridge University Press, 216 p.

SHARP, Gene (1968): La lucha política Noviolenta: criterios y métodos, trad. Jaime González, Albert Einstein Institution, Massachussets, 114 p.

SHARP, Gene (2014): De la dictadura a la democracia. Un sistema conceptual para la liberación, Madrid, Dharana, , $91 \mathrm{p}$.

SHIVA, Vandana (1998): La praxis del ecofeminismo: biotecnología, consumo y reproducción, Barcelona, Editorial Icaria, 238 p.

SHIVA, Vandana (2006): Manifiesto para una democracia de la tierra: justicia, sostenibilidad y paz, Barcelona, Ediciones Paidós, 229 p.

SIMONNET, Dominique (1980): El ecologismo, Madrid, Gedisa, 188 p. 
SPERANZA, Andrea (2006): Ecología profunda y autorrealización: introducción a la filosofía ecológica de Arne Naess, Buenos Aires, Biblos, 125 p.

STIEHM, Judith (1968): "Nonviolence is two", Sociological Inquiry, 38, Winter, 23 30.

THOMPSON, E. P. (1988): William Morris, de romántico a revolucionario, Valencia, Edicions Alfons el Magnànim, $762 \mathrm{p}$.

THOREAU, Henry D. (1995): Sobre el deber de la desobediencia civil (ed. or. 1849), Irún, Iralka, 86 p.

THOREAU, Henry D. (2005): Walden (ed. or. 1854), Edición crítica de J. Alcoriza y A. Lastra, Madrid, Cátedra, 357 p.

WAAL, Frans de y otros (2007): Primates y filósofos. La evolución de la moral del simio al hombre, trad. de Vanesa Casanova Fernández, Barcelona, Paidós, 256 p.

WAAL, Frans de y otros (2011): La edad de la empatía. Lecciones de la naturaleza para una sociedad más justa y solidaria, trad. de Ambrosio García Leal, Barcelona, Tusquets, $358 \mathrm{p}$.

WILSON, Edward O. (2012): La conquista social de la tierra, trad. de Joandomènec Ros, Barcelona, Debate, 381 p. 